\title{
Recent advances in the treatment of male sub-fertility
}

\author{
PATRICK BYE \\ M.B., B.Chir., D.C.H. \\ Schering Chemicals, Burgess Hill, Sussex
}

\begin{abstract}
Summary
Recent advances in our understanding of the physiology of reproduction in the male are reviewed. An hypothesis concerning the role of androgens in spermatogenesis is discussed.
\end{abstract}

THE study of male fertility has had so little attention that only in the last few years has it even acquired a name but, although andrology is now recognized as a separate medical field, there are still very few specialists working in it. Investigation of childless couples is still largely dealt with by gynaecologists who, although during the past two decades they have added to their traditional surgical skills an extensive knowledge of female endocrinology, have made very little advance in their understanding of male reproductive physiology. In his textbook of obstetrics and gynaecology, Baird (1969) says 'The treatment of male sterility is difficult and the results are disappointing'. Jeffcoate (1967) in his 'Principles of Gynaecology' states: 'So far I have never seen semen improved by any form of medical treatment'.

But the problem is not simply one of disseminating information, since in biological research generally the hormonal control of fertility in the male is much less well understood than in the female. In the female, the maturation of the follicle and ovulation are clearly dependent on gonadotrophins. The hormones produced by the ovary have their role to play later in reproduction, but we should expect the analogy with spermatogenesis to end at the production of the mature gamete. Therefore, there was no reason to assume that testicular androgens had any role in spermatogenesis itself, the role of the androgens apparently being to nourish and sustain mature spermatozoa through stimulation of the prostate and seminal vesicles in the same way that the ovarian hormones sustain the ovum through their effects on the female genital tract.

Jeffcoate says that the most rational hormone therapy for inactive seminiferous tubules is the administration of FSH and that, although gonadotrophins from animal sources are ineffective, claims have been made for the value of human gonadotrophins. However, unlikely as it might seem, the possibility that the testis might be a target for its own endocrine secretion was considered years ago, and androgens were readily shown to stimulate spermatogenesis in a wide range of animal experiments. Consequently, attempts were made to do so in subfertile man. Spence and Medvei (1959) reported that thirty cases of defective spermatogenesis treated with various androgen preparations had considerable success in terms of pregnancies, but oddly enough with little change in the quality of the semen. Scepticism about the value of androgens in stimulating spermatogenesis persisted, and Baird (1969) says in his book: 'There is no evidence that the androgens have any direct effect on spermatogenesis'.

Even if we accept that the animal findings are probably relevant to humans, we come up against the problem that any dosage of androgens hitherto considered worth trying clinically severely depresses gonadotrophin secretion, and, according to the orthodox view, gonadotrophins play a role in spermatogenesis, not solely through their influence on the production of androgens, but also directly. Thus, the answer might appear to be to use a large dose of androgen, accepting that it will markedly suppress gonadotrophins, and to replace these with an exogenous supply. Unfortunately, gonadotrophins cannot yet be synthesized, antibodies are soon developed to gonadotrophins of animal origin so that they rapidly become ineffective and gonadotrophins of human origin are scarce and expensive. Great interest, therefore, was aroused by the synthesis of mesterolone, 1-methyl-5 $\alpha$-dihydrotestosterone. As synthetic androgens go, mesterolone proved to be rather weak, but it has the surprising and unique property that, at a dosage sufficient to produce androgenic stimulation of peripheral target tissues, it has little or no effect on gonadotrophin secretion.

This is the rationale for using it alone in the treatment of defective spermatogenesis, despite the fact that other androgens have repeatedly been shown to suppress spermatogenesis. How can we explain this rather unusual separation of properties? By far the most potent class of sex hormones in the suppression of gonadotrophin secretion is that of the oestrogens. The distinctive feature of oestrogens as compared 
with the other classes of hormonal steroids is that the A-ring is aromatic, as in benzene and its compounds. Now, typically, androgens are metabolized to a measurable degree by aromatization of the A-ring, and almost certainly the oestrogenic metabolites so formed are largely responsible for the negative feedback exerted by androgens on the pituitary. Mesterolone has no oestrogenic action in biological systems and aromatized metabolites have never been detected in men.

How are we to measure the response of the subfertile male to treatment? One might say that the proof of the pudding is in the eating and, in a large enough series, pregnancies occurring in childless couples of some years' standing should be convincing proof. It is usual, however, to assess treatment by means of semen analyses. The parameters looked at have been many, but the biochemical ones such as the fructose content are determined chiefly by the functions of the prostate and seminal vesicles, and are also dependent on the duration of storage and the condition of the stored semen between ejaculation and examination. The most important parameters, therefore, are the sperm count and the percentages of sperms that look normal and that move normally. The sperm count is usually given per millilitre of semen, and this is of course influenced by the volume of fluid contributed to the ejaculate by the accessory glands. But to use the total ejaculated sperm count might be no more reliable, since this could be influenced by variation in the force of ejaculation. It is known that the sperm count falls when ejaculation occurs more often than every 3 days, and counts should, therefore, always be taken after a standard period of abstinence, which is usually 3 days. Variations in sperm counts are great (Fig. 1) and clinical experience indicates that it is unwise, as many people have been tempted to do, to put a figure on a minimum fertile count. If $60 \mathrm{million} / \mathrm{ml}$, for instance, is taken as the lowest figure for a normal sperm count below

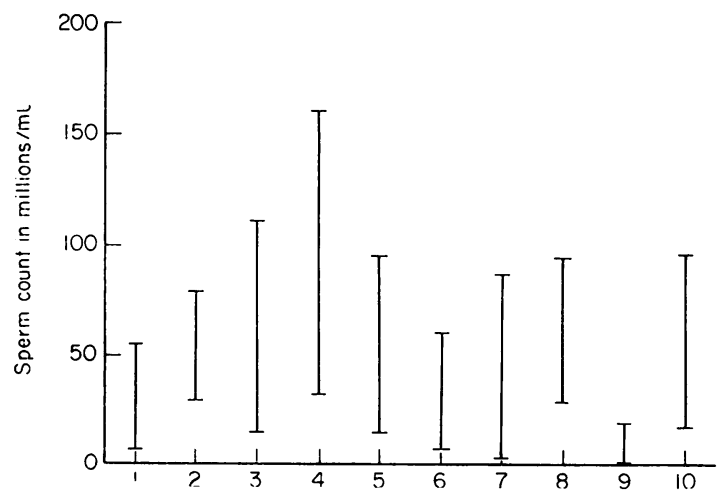

FIG. 1. Range of sperm counts in semen specimens for ten healthy volunteers (Van Zyl, 1972). which fertility is likely to be subnormal and yet it is acknowledged that conception may be possible when sperm counts as low as 10 million have been found, the count is of little value in assessing the patient's status. Where it is likely to be of value, however, is in monitoring the response to treatment. Van Zyl (1972) found a linear relationship between conception rate and the percentage of motile sperms when the percentage fell between 10 and 70 . However, there is far from uniform agreement about what constitutes a normal percentage motility. Baird (1969) says that $90 \%$ of sperm are motile in a normal specimen. Jeffcoate (1967) says that usually $70-80 \%$ are motile when the specimen is collected. But Davidson (1974) examined thousands of sperm specimens and never counted more than $78 \%$ of motile sperms.

Motility is peculiarly sensitive to conditions of storage before examination, but abnormal sperm morphology should not change. There are always abnormal forms present of the order of $10-20 \%$, and a substantially higher figure may still be compatible with adequate fertility. To complicate matters further, Lacy (1974) has recently found that in the semen of sub-fertile males, sperms that appear normal by ordinary microscopy show considerable disorganization by scanning electron microscopy. He believes the defect to involve the meiotic division, a stage of spermatogenesis for which androgens appear to be essential. Therefore, although we should not use sperm analyses to make confident predictions about the patient's fertility (unless of course the abnormality is extremely gross), we can use them to monitor progress' Figure 2 (taken from a paper by Hendry et al., 1973) gives a fairly convincing impression that treatment with mesterolone has been beneficial.

Z.l. age 30

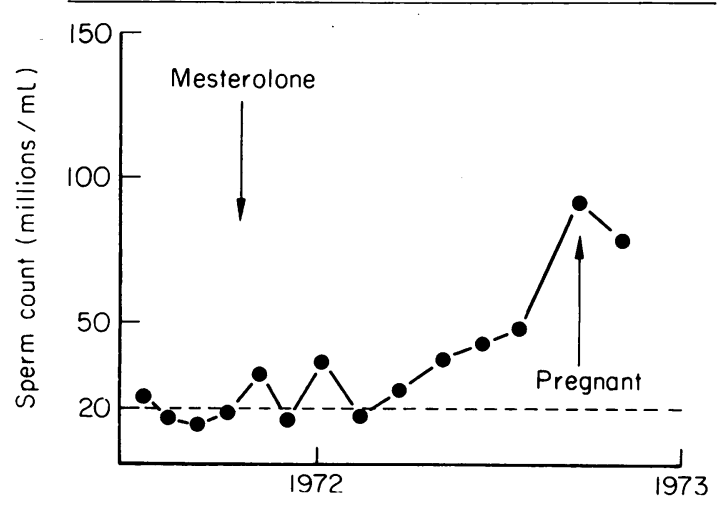

FIG. 2. Individual response to mesterolone (Hendry et al., 1973).

Table 1 shows the response to treatment of sixtynine patients who received $100 \mathrm{mg}$ of mesterolone 


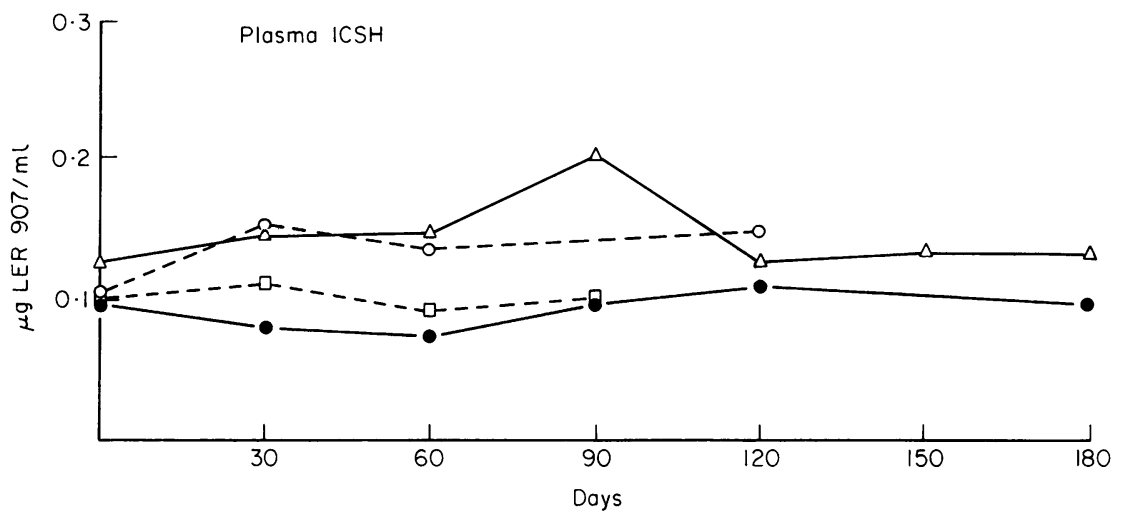

FIG. 3. Results of the determination of plasma ICSH in four patients receiving mesterolone for 3-6 months (Hendry et al., 1973).

TABLE 1. Mesterolone $100 \mathrm{mg}$ daily for 1 year. Results obtained in sixty-nine patients with initial counts of less than $40 \mathrm{million} / \mathrm{ml}$, expressed as percentage showing improvement to more than $\mathbf{4 0}$ million $/ \mathrm{ml}$

\begin{tabular}{lccccc}
\hline & & \multicolumn{3}{c}{ Initial sperm count (millions/ml } \\
\cline { 2 - 6 } & & Aspermic & $1-10$ & $11-20$ & $21-40$ \\
\cline { 2 - 6 } & Number & 7 & 24 & 27 & 11 \\
\hline 3 months & 69 & 0 & $17 \%$ & $22 \%$ & $27 \%$ \\
6 months & 63 & 0 & $5 \%$ & $35 \%$ & $38 \%$ \\
9 months & 37 & - & $29 \%$ & $47 \%$ & $50 \%$ \\
12 months & 16 & - & $16 \%$ & $50 \%$ & $2 / 2$ \\
Pregnancies & & - & 7 & 4 & 2 \\
\hline
\end{tabular}

From Hendry et al., 1973.

TABle 2. Mesterolone $100 \mathrm{mg}$ daily for 1 year. Results obtained in twenty-four patients with initial counts of less than 10 million/ml, expressed as percentage showing improvement to more than 20 million/ $\mathrm{ml}$

\begin{tabular}{lc}
\hline & $\begin{array}{c}\text { Sperm count more than } \\
20 \text { million/ml }\end{array}$ \\
\hline 3 months & $29 \%$ \\
6 months & $33 \%$ \\
9 months & $57 \%$ \\
12 months & $50 \%$ \\
\hline
\end{tabular}

From Hendry et al., 1973.

daily for a year. Each figure shows the percentage of patients whose sperm count had risen to more than $40 \mathrm{million} / \mathrm{ml}$. They are divided into four groups on the basis of their sperm counts before treatment. Patients with azoospermia showed no response. In terms of ability to raise the sperm count above 40 millions, it made little difference whether the patients' initial sperm counts were in the 11-20 million range or in the $21-40$ million range, about a quarter having responded to that extent in 3 months, a third within 6 months and half within 9 months and half within 12 months. Although the figures for those whose initial sperm counts were below 10 million are not so good (as shown in Table 2), the percentage of those patients whose sperm counts were raised to above 20 millions were much the same. Thirteen pregnancies occurred in the wives of these sixty-nine patients, giving a success rate of $19 \%$. Figure 3 shows that, in the four patients studied, treatment with 100 mg of mesterolone daily for 3-6 months did not produce detectable suppression of the plasma levels of ICSH.

So, without being spectacularly successful, mesterolone seems to be valuable in at least some cases of a condition for which hormone therapy has hitherto been generally considered useless.

Mesterolone is, as synthetic androgens go, not particularly strong in its effect on the secondary sexual organs yet, in stimulating spermatogenesis, it is much more potent than others. This difference could be accounted for if both gonadotrophins, which mesterolone does not suppress, were needed, in addition to androgens, for stimulating spermatogenesis. But this argument cannot be used when gonadotrophins have been suppressed by other means. Lacy (1974) has recently found that in rats whose gonadotrophin production is completely suppressed by oestrogens, mesterolone can maintain completely normal testicular weight and apparently completely normal spermatogenesis.

It appears then that gonadotrophins are not essential for spermatogenesis, in which they play no direct role, and that their place can be taken by androgens. If this is so, some other explanation must be sought for the extremely high potency of mesterolone in stimulating spermatogenesis, despite its relative weakness in stimulating the secondary sexual organs. Two possible explanations seem likely. One is 
that mesterolone has a superior ability to penetrate the seminiferous tubules, which, of course, an androgen must do in order to stimulate the germinal epithelium. The Sertoli cells which, for want of a better name, used to be called 'supporting cells', do not contribute to the formation of gametes, but clearly have a metabolic function. In the last few years electron microscopy has shown that tight junctions exist between the Sertoli cells so that no germinal cells are in direct contact with the walls of the seminiferous tubules. It has been shown that there are steroid receptors in all the tubule cells, and that labelled steroids can enter the tubule, although of course the presence of the label within the tubule does not enable us to say in what form it is present. However, steroids certainly enter the tubules with different facility, corticosteroids, for instance, having little ability to do so (Setchell, 1967). But it is not possible to say whether differential ability to penetrate the seminiferous tubules plays any part in the superior influence of mesterolone on spermatogenesis.

The most probable explanation is connected with the discovery of the function of the Sertoli cells. It has now been clearly established that the Sertoli cells possess all the enzymes necessary for the conversion of various precursors to testosterone, and to synthesize testosterone even from the parent substance of all the steroids, cholesterol (Lacy et al., 1973). Of course, the fact that cells have the potential to carry out a certain metabolic process does not necessarily mean that in life that process is carried out or, if so, to a significant extent. There can be little doubt that these processes do occur, since changes in the intracellular organelles and the concentrations of certain enzymes and sterols indicative of changing steroid metabolism in the Sertoli cells of many seasonal submammals follow the pattern of seasonal variation in spermatogenesis (Lofts, 1968). Moreover, these changes can be produced in vitro by the direct action of FSH on dissected tubules, whereas ICSH, which controls the activity of the Leydig cells, has no such effect on the tubules (Dorrington, Vernon and Fritz, 1973; Lacy, 1973). This is in accordance with the generally accepted roles of FSH and ICSH or LH, that is, that FSH is the chief influence in gamete production and $\mathrm{LH}$ in the hormones required for stimulating secondary sexual functions. So, if there is a separate source of androgens within the seminiferous tubules, it must surely be part of the normal physiological control of spermatogenesis, and it has been shown that for the one process that is unique to the gonads, the meiotic division, androgens are indispensable (Clermont and Harvey, 1967).

It might be postulated that the androgens produced by the Sertoli cells are no more than a non-specific contribution to a pool but, if this were so, the separate control of production outside and inside the tubules by the different gonadotrophins would be a very odd mechanism indeed. There was in vivo evidence from the same experiments that this difference in gonadotrophin control was significant since, in the hypophysectomized rats from which these tubules were dissected, diminished production of androgens by the Leydig cells of the interstitial tissue was shown by a reduction in weight of the seminal vesicles, while, at the same time, androgen production within the tubules was shown to have been stimulated by administering FSH. Conversely, when LH was used, androgen production by the Leydig cells was increased while that within the tubules was generally reduced (Lacy et al., 1973).

So, the ability of androgens to stimulate spermatogenesis forced us to conclude that the old model of pituitary-testicular function was wrong, and we had to accommodate in any new model the idea that the testis was a target tissue for its own endocrine secretion. Oddly enough, this newest evidence that there are two anatomically and probably functionally separate sources of androgens within the testis, each of which is responsive to a single gonadotrophin, brings us back to something like the original model after all, with LH stimulating the production of androgens from the Leydig cells in the interstitial tissue, and FSH the production of androgens from Sertoli cells within the seminiferous tubules, but with the necessary androgenic stimulus to spermatogenesis being provided by the intratubular source, rather than by the production of the Leydig cells, whose responsibility is the development and maintenance of extratesticular androgen functions.

If this is so, there is no good reason why we should assume that the androgens produced inside the tubule are identical with the ones outside.

Many steroids with androgenic activity are found in the body, but it was taken for granted for decades that testosterone was the 'real' androgen, and that the others occurred either as intermediary metabolites or degradation products of testosterone. In the last few years, however, since it was discovered that the reduced form, $5 \alpha$-dihydrotestosterone, was as effective as testosterone, or even more so in some tissues such as the rat prostate, there has been much speculation about the important androgens, some people even going so far as to speculate that testosterone itself was no more than an intermediary metabolite in the production of $5 \alpha$-dihydrotestosterone. This view does not seem to be tenable, but $5 \alpha$-dihydrotestosterone is an important androgen.

Androgens in sufficient dosage can stimulate spermatogenesis. This was shown with testosterone propionate as long ago as 1934 . However, it has now been shown that the response to various androgens or androgenic precursors varies according to whether 
they are given for maintenance purposes immediately after hypophysectomy or after the suppression of gonadotrophin production with oestrogens (Harvey, 1966) or after sufficient time has been allowed for considerable testicular atrophy to occur (Boccabella, 1963). It is clearly the long-term deficiency that is analogous to the clinical condition in sub-fertile men. Lacy and his colleagues recently found mesterolone, in the form of an injectable ester, to be successful in fully restoring apparently normal spermatogenesis after long-term suppression of gonadotrophin production in the rat. They have not been able to obtain comparable results with other androgens (Lacy et al., 1969).

It seems that, in maintenance experiments immediately after hypophysectomy or after gonadotrophin suppression, the seminiferous tubules retain the capacity to synthesize an androgen needed for spermatogenesis, and that this androgen is not testosterone. Mesterolone is unique among synthetic androgens in being a derivative not of testosterone but of the reduced form, $5 \alpha$-dihydrotestosterone, but, whereas the natural hormone is of limited effectiveness because of its rapid rate of breakdown, mesterolone, which is methylated in the 1-position, is much more stable. Therefore, it may well be that, great as mesterolone's advantage in not suppressing gonadotrophin production undoubtedly is, its ability to obviate certain metabolic steps in the stimulation of spermatogenesis may be of equal, or even greater, importance. Lacy's work in the rat remains to be confirmed in the human, but if the same apparently complete maintenance of spermatogenesis in the absence of gonadotrophins can be shown, there will no longer be the need to postulate any direct role for gonadotrophins in spermatogenesis. The way would then be open to use mesterolone by mouth in even larger doses than is recommended at present, since some suppression of gonadotrophins would then be unimportant. Of course, the toxicity of steroids in large doses exerts some restraint on their use, but mesterolone is not alkylated in the 17-position and is, therefore, unlikely to present any serious problems of liver toxicity, even in somewhat higher dosage than is now used.

But most cases of male infertility must still be labelled idiopathic, and there is no reason to assume that a large percentage of them will, therefore, benefit from any androgen therapy. However, there are two sources of androgen production, and it is the source outside the tubules-the one that is not apparently concerned with spermatogenesis-that produces the systemic manifestations of androgenicity. Those manifestations, when normal, do not in themselves prove that androgen deficiency within the seminiferous tubules is not present. Consider for comparison the so-called 'fertile eunuch', who has normal spermatogenesis but very little secondary sexual development. Presumably, in such cases the production of androgens by the Sertoli cells within the tubules is normal, while production in the Leydig cells is not.

In conclusion, no clinical or laboratory test of androgenicity at present can enable us to determine the possibility of a response to mesterolone treatment. Biopsy demonstration of non-obstructive azoospermia is perhaps the only evidence we should accept that all treatment will be hopeless.

\section{References}

BAIRD, D. (1969) Combined Textbook of Obstetrics and Gynaecology, 8th edition. E. \& S. Livingstone Ltd, Edinburgh.

Boccabella, A.V. (1963) Re-initiation and restoration of spermatogenesis with testosterone propionate and other hormones after a long-term post-hypophysectomy regression period. Endocrinology, 72, 787.

Clermont, Y. \& HaRvey, S.C. (1967) In: Endocrinology of the Testis (Ed. by G. E. W. Wolstenholme and M. O'Connor). Ciba Foundation Colloquia on Endocrinology, 16, 173. Churchill, London.

Davidson, H.A. (1974) Personal communication.

Dorrington, J.H., Vernon, R.E. \& Fritz, I.B. (1973) Effect of FSH on the 3', 5' AMP content of seminiferous tubules. In: Proceedings of the IVth International Congress of Endocrinology, Washington 1972. Abstract No. 537, Excerpta Medica.

HARVEY, S.C. (1966) Effect of hormones on spermatogenesis in the rat. Ph.D. thesis. McGill University.

Hendry, W.F., Sommerville, I.F., Hall, R. \& Pugh, R.C.B. (1973) Investigation and treatment of the sub-fertile male. British Journal of Urology, 45, 684.

Jeffconte, T.N.A. (1967) Principles of Gynaecology. Butterworths, London.

LACY, D. (1967) The seminiferous tubule in mammals. Endeavour, 26, 101.

LACY, D. (1973) Androgen dependency of spermatogenesis and the physiological significance of steroid metabolism in vitro by the seminiferous tubules. In: The Endocrine Function of the Human Testis. Vol. 1. Academic Press, New York and London.

LACY, D. (1974) Personal communication.

LaCy, D., Bass, J.J., Bell, J.B.G., Collins, P.M., Fyson, P., Pettitt, A.J. \& Pudney, J. (1973) Steroid metabolism by the seminiferous tubules of mammals and its biological and medical significance. In: Proceedings of the IVth International Congress of Endocrinology, Washington 1972. Excerpta Medica.

LACY, D. \& Rotblat, J. (1958) Effects of ionising radiation on the testis of the rat with some observations on its normal morphology. In: Proceedings of the IVth International Congress on Electron Microscopy, Berlin, Vol. 2. Springer-Verlag, Berlin, 484.

Lacy, D., Vinson, G.P., Collins, P., Bell, J., Fyson, P., Pudney, J. \& Pettitt, J. (1969) In: Progress in Endocrinology, Proceedings of IIIrd International Congress of Endocrinology, Mexico 1968. Excerpta Medica.

LofTs, B. (1968) Patterns of testicular activity. In: Perspectives in Endocrinology (Ed. by E. V. M. Barrington and C. Barker-Jorgensen. Academic Press, New York and London. 
Setchell, B.P. (1967) The blood testicular fluid in sheep. Journal of Physiology, 189, 63.

Spence, A.W. \& Medvei, V.C. (1959) Testosterone in defective spermatogenesis. Lancet, i, 124.
VAN ZYL, J.A. (1972) A review of the male factor in 231 infertile couples. South African Journal of Obstetrics and Gynecology, 10, 17. 